\title{
Extension of the Pulsed Power Supply Network of ASDEX Upgrade by a Set of Compact Modular Generators
}

\author{
C.-P. Käsemann ${ }^{\mathrm{a},{ }^{*}}$, M. Huart ${ }^{\mathrm{a}}$, L. v. Lieshout ${ }^{\mathrm{b}}$, D. Habel ${ }^{\mathrm{c}}$, F. Stobbe ${ }^{\mathrm{a}}$ and the ASDEX Upgrade Team \\ ${ }^{a}$ Max-Planck-Institut für Plasmaphysik (IPP), EURATOM Association, Boltzmannstraße 2, D-85748 Garching, Germany \\ ${ }^{b}$ Imtech Vonk BV, Modem 30, NL-7741 MJ Coevorden, The Netherlands \\ ${ }^{c}$ Piller Germany GmbH \& Co. KG, Abgunst 24, D-37520 Osterode (Harz), Germany
}

Some years ago, ASDEX Upgrade (AUG) examined its future power supply needs. The experimental program could make use of an extension of the IPP pulsed energy storage, both to allow new scenarios at higher plasma current to be investigated, as well as to allow longer plasma flat-top time. Studies performed in 2001 and 2002 by IPP and external collaborators showed that an attractive solution for this extension is a parallel connection of commercially available compact flywheel generators. Especially the main challenges of this system will be explained in the paper. Further on, the paper will present the parallel and stand-alone mode of operation, analyse the results of measurements obtained during commissioning, compare them to the calculated design values and report on the performance achieved during AUG plasma experiments and additional heating operation.

Keywords: ASDEX Upgrade; Flywheel generator; Power supply

\section{Introduction}

The AUG ohmic heating transformer and the poloidal field coils are supplied by thyristor converter units with an installed apparent power of about 600 MVA. Further, the high voltage power supplies for Additional Heating have a total installed apparent power of about 100 MVA. All of these systems are supplied by two large flywheel generators EZ3 and EZ4. The pulsed $10.5 \mathrm{kV}, 110-85 \mathrm{~Hz}$ supply network composed of these generators has a total apparent power of 364 MVA and a deliverable energy of 1268 MJ. The power supply network is shown in Fig. 1. These generators dissipate fair no-load losses when running for test purposes. Avoiding the start-up of these generators in the morning and shut-down in the evening would be very profitable in view of kWh cost saving.

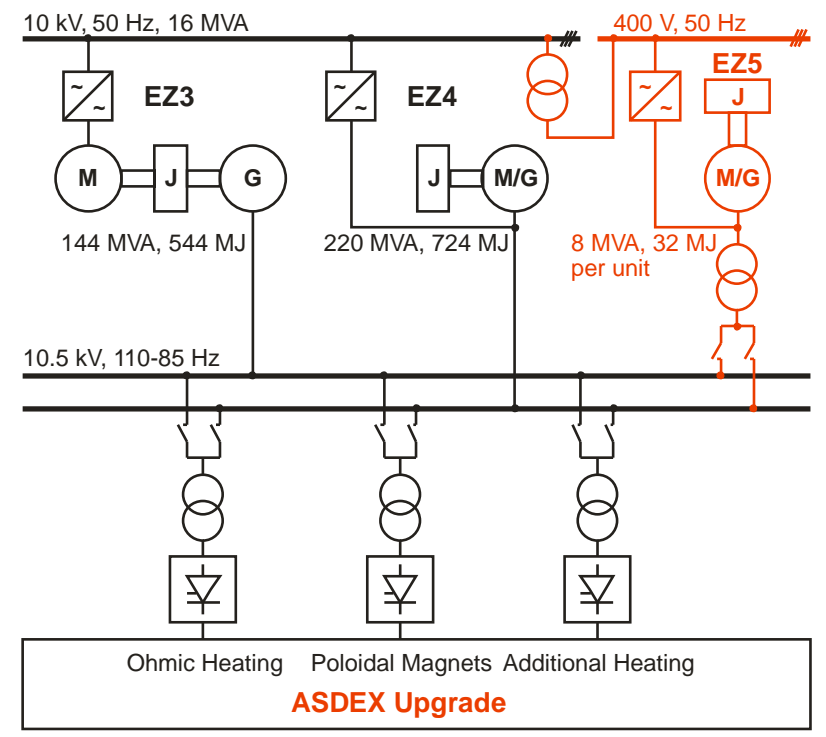

Fig. 1. AUG Pulsed Power Supply Network

\section{Application}

The Compact Modular Energy Storage System, called EZ5, has been simulated and designed in full comprising of up to five Energy Storage Units (ESUs), each rated $8 \mathrm{MVA}$ / $32 \mathrm{MJ}$. The system is designed at being operated in parallel to one of the generators EZ3 or EZ4 as well as being able of "stand-alone" operation. An ESU consists of four Energy Storage Modules (ESMs). It is possible to operate the ESU with some ESMs outof-service for repair or fault finding. The same principle extends to the ESUs when the system includes several of them in parallel.

The EZ5 operates in parallel to one of the big flywheel-generators without system instabilities, taking account of the AUG transient loads. In stand-alone operation, the Energy Storage System is capable of maintaining a stable system voltage free of voltage fluctuations on the $10.5 \mathrm{kV}, 100 \mathrm{~Hz}$ busbar for testing purposes [1].

\section{Power Supply Concept}

\subsection{Overview}

Each ESM includes as main elements a FlywheelMotor-Generator (FMG) in a separate cabinet, an Excitation Power Supply (EPS), a Module Inverter Drive (MID) and a Module Switching Cabinet containing the EPS, the MID and all of the low voltage switches shown around each module (Fig. 2). As FMG a commercially available vertical axe flywheel system for the application of UPS is used: The Powerbridge from Piller Germany.

The energy stored within an ESM is proportional to the square of the speed of the rotor and can be measured as frequency of the AC output voltage of the ESM generator. The usable energy ranges from $0 \%$ at $85 \mathrm{~Hz}$ (2550 rpm) to $9 \mathrm{MJ}$ at $110 \mathrm{~Hz}$ (3300 rpm) at which point the ESM is fully charged. The main technical data is given in Table 1. 


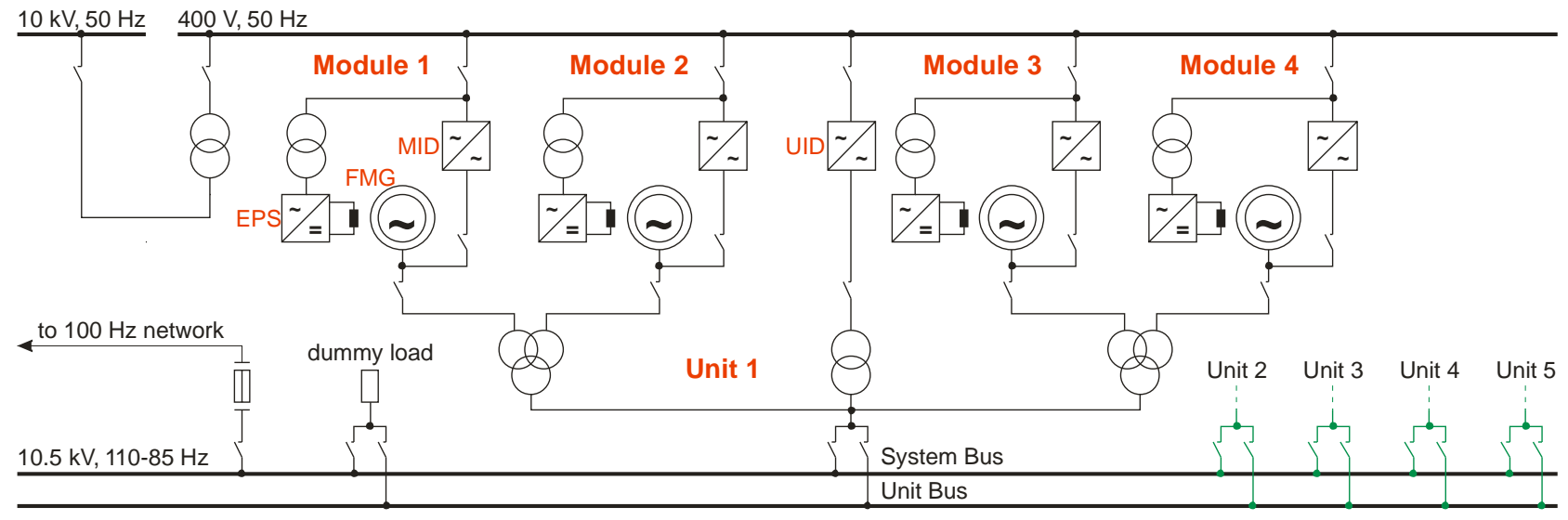

possible future extension

Fig. 2. EZ5 Power Supply Configuration

FMG: Flywheel Motor Generator; EPS: Excitation Power Supply; MID: Module Inverter Drive; UID: Unit Inverter Drive

A synchronous machine mounted on a shaft along with the flywheel enables energy to be coupled in and out. The stator of this four-pole machine is shrink-fitted into the tapered housing, so that the winding and core losses can be dissipated via the outer wall. The synchronous machine is excited electrically and without slip rings via the exciter located at the upper end of the shaft. The rotating rectifier is positioned above (Fig. 3). The whole FMG is built in a vacuum-proof casing and is filled with helium to reduce the friction losses and to improve the cooling. The casing is air-cooled externally.

Table 1: EZ5 Main Data

\begin{tabular}{ll}
\hline \multicolumn{3}{l}{ Main technical data of an ESM } \\
\hline Output voltage & $800 \mathrm{~V} \mathrm{AC}$ \\
Output frequency & $110-85 \mathrm{~Hz}$ \\
Useable energy content & $9 \mathrm{MJ}$ \\
Speed range & $3300-2550 \mathrm{rpm}$ \\
Total mass of rotor & $2950 \mathrm{~kg}$ \\
Total inertia of rotor & $376 \mathrm{kgm}^{2}$ \\
Nominal pulsed power & $2 \mathrm{MVA}(\cos \varphi=1)$ \\
\hline \multicolumn{2}{l}{ Main system data of an ESU } \\
\hline Stored energy at $100 \mathrm{~Hz}$ & $74.1 \mathrm{MJ}$ \\
Nominal pulsed power & $8 \mathrm{MVA}(\cos \varphi=0.95)$ \\
Nominal pulse length & $4.7 \mathrm{~s}$ \\
\hline
\end{tabular}

\subsection{Design and Simulation Stage}

During the basic design stage great effort was put into measuring and defining the synchronous generator machine characteristics that were needed to be known in detail for the simulations. From thereof all operating conditions were examined by means of the Simplorer simulation package. This was further supported by the analysis carried out by the University of Rostock / D. Specially the rotating exciter and rectifier made it hard to finalise the simulations of the stand-alone operation. Additional measurements of the characteristics were carried out to understand the double time constant reaction of the synchronous generator voltage. Finally the controller algorithm could be assessed.

\subsection{Start-Up and Synchronization Process}

Each ESM is accelerated by its Module Static Inverter Drive from standstill to the module synchronization frequency of $85 \mathrm{~Hz}$. After synchronization, the Unit Static Inverter Drive takes over to further accelerate the ESMs of one ESU to the reference speed and to control the speed and phase in order to synchronize the ESUs among each other and to the EZ3/EZ4 network. After synchronization to the EZ3/EZ4 network, acceleration of the ESUs to operational speed for an AUG pulse is achieved by deriving power, through the $10.5 \mathrm{kV}, 100 \mathrm{~Hz}$ network, from the drive system of EZ3 or EZ4. In stand-alone operation, the UIDs are used to accelerate the ESUs to the starting frequency for an Additional Heating pulse. The UID is further needed to brake down an ESU, after disconnection from the other parallel connected ESUs, from the idling frequency to $20 \mathrm{~Hz}$.

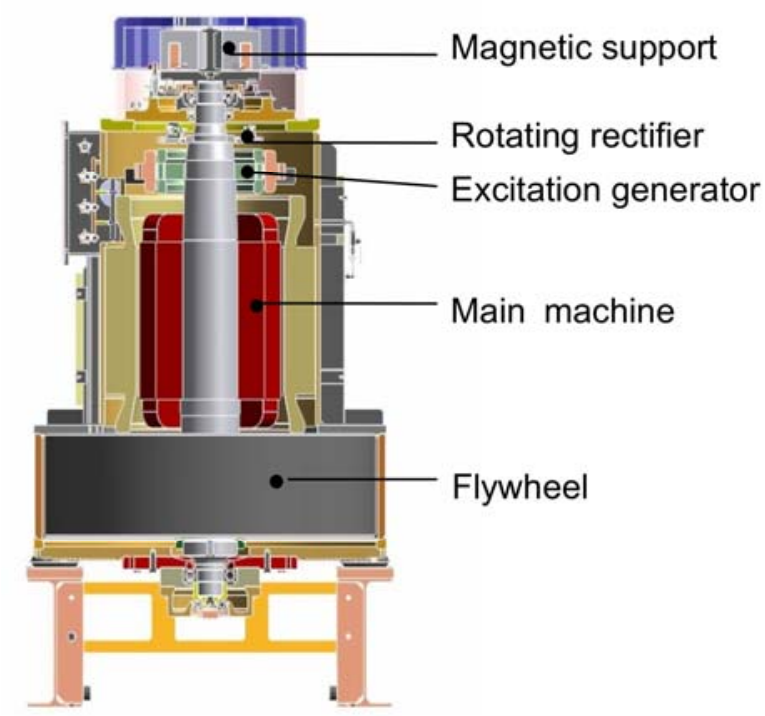

Fig. 3. Cross Section of Flywheel-Motor-Generator

Fife different synchronization processes have to be distinguished:

(a) "Synchronization" of the first ESM within an ESU. 
(b) Synchronization of the remaining on-line ESMs to the ESU.

(c) Synchronization of an ESU to the system bus, in parallel to the generator EZ3 / EZ4 or to another ESU.

(d) "Synchronization" of the first ESU to the system bus in stand-alone operation.

(e) "Synchronization" of an ESU to the unit bus for testing purposes.

The module synchronization process is different from unit synchronization and uses different hard- and software. Module and unit synchronization can take place at any frequency in the range of $85-100 \mathrm{~Hz}$.

\section{Example: Synchronization Process (c)}

For reasons of redundancy and diversity, the synchronization is controlled by two independent devices, the Piller controller board and a standard Piller synchronization card. Only if both boards confirm that the voltage, frequency and phase are within the allowed limits of $1 \mathrm{~Hz}$ frequency deviation and $15^{\circ}$ phase shift the synchronizing circuit-breaker is closed.

The controller board is located in the UID cabinet and is interfaced with the speed and frequency regulation of the UID that controls the slip frequency and the phase shift. The voltage signals are derived from the $10.5 \mathrm{kV}$ level by two sets of series connected transformers (Fig. 4). The second set is connected in a certain open delta configuration to the input of the controller board, so that the line voltages are added as shown in Fig. 4. The length of the resulting voltage vector is proportional to the amplitude of the voltage on the $10.5 \mathrm{kV}$ level and the vector turns with an angular velocity proportional to the frequency on the $10.5 \mathrm{kV}$ network.

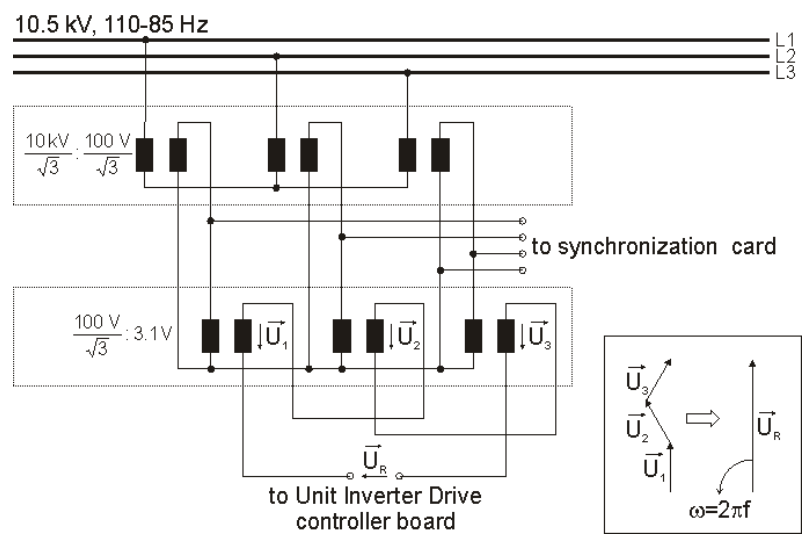

Fig. 4. Voltage Sensing for Unit Synchronization.

The analogue synchronization card is normally used for synchronization of Piller UPS systems. It compares the phasing of the voltages to be synchronized. Furthermore, the board detects power failures. For synchronization, the voltage needs to be in a range of 6 $11.5 \mathrm{kV}$.

\subsection{Protection and Selectivity}

For easier fault finding, special attention has been paid on the first failure detection and on the selectivity between units, between modules of the same unit and between protections within one module. A faulty module or unit will trip and isolate itself automatically to preserve the integrity of the whole system. This "offline" status is determined by the open status of the disconnectors at the $800 \mathrm{~V}$ and $10.5 \mathrm{kV}$ sides. When an ESM or ESU is off-line, the faults of this component are ignored at the system level. For a unit, a minimum of three ESMs need to be on-line.

The setting of the system overcurrent protection will be selected depending on the number of units installed within the EZ5 system (one as a minimum and 5 as a maximum). The possible fault current levels are shown in Table 2.

Table 2: EZ5 Fault Current Levels

\begin{tabular}{lrr}
\hline \multicolumn{4}{l}{ Faults at 800 V side (current at $800 ~ \mathbf{~ l e v e l )}$} \\
\hline Frequency & $85 \mathrm{~Hz}$ & $110 \mathrm{~Hz}$ \\
$\mathrm{I}_{\max }$ from faulty ESM & $10.7 \mathrm{kA}$ & $8.3 \mathrm{kA}$ \\
$\mathrm{I}_{\max }$ from other ESUs & $36 \mathrm{kA}$ & $27.8 \mathrm{kA}$ \\
\hline Faults at 10.5 kV side (current at & $\mathbf{1 0 . 5} \mathbf{~ k V}$ level) \\
\hline $\mathrm{I}_{\max }$ from ESM in faulty ESU & $0.64 \mathrm{kA}$ & \\
$\mathrm{I}_{\max }$ from other ESUs & $2.6 \mathrm{kA}$ & $2.1 \mathrm{kA}$ \\
$\mathrm{I}_{\max }$ from EZ4 & $81 \mathrm{kA}$ & $62.6 \mathrm{kA}$ \\
$\mathrm{I}_{\max }$ from EZ3 & $40 \mathrm{kA}$ & $31 \mathrm{kA}$ \\
\hline
\end{tabular}

\section{Commissioning}

Commissioning has been performed on two locations: A Factory Acceptance Test (FAT) at the test stand of Piller in Bilshausen / D and a Site Completion Test, followed by the Site Acceptance Test, at the IPP site in Garching / D. The FAT mainly comprised no-load and light load testing with up to four ESMs. An 8/4/2 MW resistive dummy load, part of the delivery, was used for initial power testing and stand alone testing at IPP site. Hereafter, only a limited number of test topics have been selected for discussion.

\subsection{Commissioning with a Resistive Dummy Load}

The basic power testing comprised synchronization of one ESM after another followed by stand-alone power testing on the resistive dummy load.

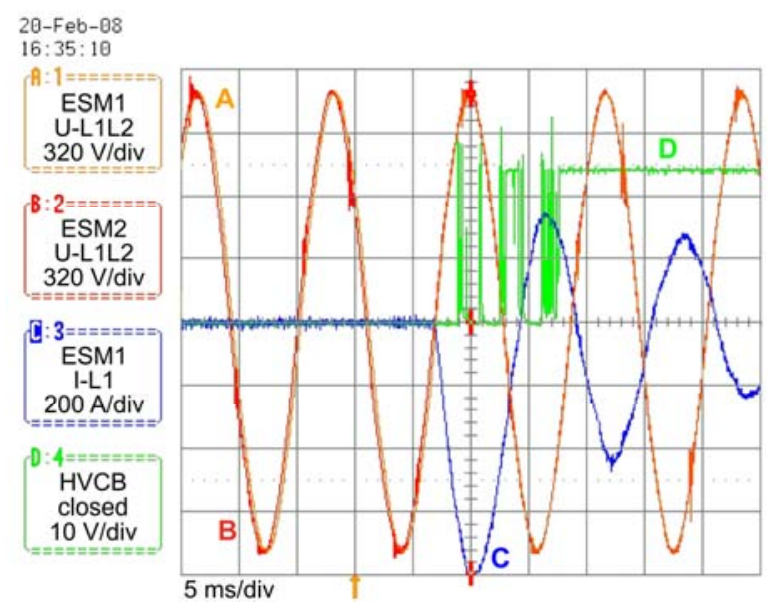

Fig. 5. Synchronisation of ESM 1 to ESM 2, 3 and 4. 
For module synchronization, switching is released when the voltage level is within $5 \%$ and the angular difference is within $15^{\circ}$. In this manner transient currents are kept low. Maximum transient current appears when a fourth ESM is synchronized to three others that are already on-line. Transient peak current remains within $40 \%$ when synchronizing at the minimum of $85 \mathrm{~Hz}$ (Fig. 5).

The current balancing between paralleled ESMs during $4 \mathrm{MW}$ power pulses is mainly achieved by reactive power control per ESM. The balancing of the active current between ESMs is guaranteed by the identical inertia of the FMGs. For the imbalance of the reactive currents the difference is kept within $1 \%$ of the active current component for one single pulse. For repetitive pulsing of $0.5 \mathrm{~s}$ on and $0.5 \mathrm{~s}$ off by switching of the resistive dummy load at $4 \mathrm{MW}$ the reactive current component difference remains within approx. $2 \%$.

Voltage stabilisation is measured during repetitive pulsing of $0.5 \mathrm{~s}$ on and $0.5 \mathrm{~s}$ off by switching the resistive load, as here above. The requirements are $1 \%$ steady state deviation during and between pulses, $-5 \%$ dip at switching on during $<200 \mathrm{~ms}$ and $+5 \%$ peak at switching off during < $500 \mathrm{~ms}$. Maximum transients are observed at $110 \mathrm{~Hz}$ starting frequency dips limited to $-3.2 \%$ and peaks to $+3 \%$ for the first pulse. Steady state is reached within $1 \%$ after the indicated time interval.

\subsection{Commissioning in Parallel and Stand-Alone Operation}

The acceptance testing with parallel connection to flywheel generator EZ3 (144 MVA) and in stand alone operation on IPP converter loads will be discussed.

During the period of one month the EZ5 unit has been operated in parallel with EZ3 for acceptance tests. This comprised operation during plasma pulses, test pulses and included generator trips. Power contribution up to $4 \mathrm{MW}$ was achieved successfully with $\cos \varphi$ of approx. 0.95 or better. Dynamic performance and current balance between ESMs was good. During an EZ3 trip dynamic reactive power peaks up to 13 Mvar occurred. This transient overload is handled without problems.

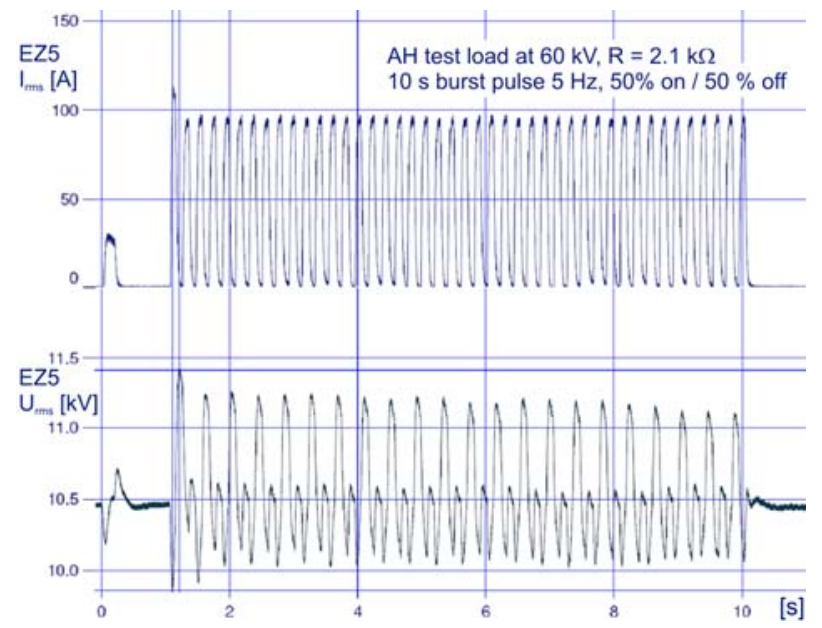

Fig. 6. Additional Heating (AH) Burst Pulse.
For stand-alone operation the EZ5 unit was connected to various Additional Heating loads. The acceptance programme included a burst of pulses during $10 \mathrm{~s}$ burst time. The burst frequency ranged from $1 \mathrm{~Hz}$ to $10 \mathrm{~Hz}$ with a duty cycle between $10 \%$ and $50 \%$. Taking $5 \mathrm{~Hz}$ with $50 \%$ duty cycle as test reference the dynamic voltage dip at burst start remains above $-5 \%$, while the peak voltage after switching off reaches $+7.5 \%$. The ESU current level during the bursts is very stable (1\%) (Fig. 6).

\section{Operational Experience}

One of the five ESUs has been built as "prototype" to prove the simulations and the calculated design under real experimental conditions. Extensive commissioning and completion tests have been carried out. Dummy load testing has shown that thanks to the simulations the controller algorithm was feasible and stand-alone operation with limited voltage under- and overshoot has been achieved.

The unit is in service during AUG operation in parallel with generator EZ3 since June 2008. Being a "first step", only, it extends the power and energy capability of the EZ3 network by about $6 \%$ and operates without major problems.

For the Additional Heating Power Supplies the unit works in stand-alone operation since March 2009. The unit is used to supply the 1.5 MVA Ion Source Power Supplies of the NBI outside AUG operation. Until now, with more than $250 \mathrm{~h}$ of operation, energy savings of 300 MWh of EZ3 and EZ4 no-load losses have been achieved.

\section{Conclusion}

EZ5 is a successful attempt to network small compact commercially available flywheel-generators to provide power pulses to fusion devices. The challenges were numerous: system stability, synchronization at module and unit levels, large fault currents, reliability despite complexity.

This network configuration provides many advantages over the purpose-built large flywheelgenerators in that it has few ancillary systems (no oil lubrication), it requires little maintenance (origin in UPS system), it is inherently safe and is self-configuring (offline status), it is easily extendable due to its modular construction (12 months delivery-time for additional units) and the system configuration is flexible (operation in parallel to a large generator (such as the large EZ3 or EZ4 units at IPP) or in stand-alone mode (island operation)).

\section{References}

[1] C. Jacob , M. Huart, F. Stobbe, I. Goldstein, H.H. Nguyen, Y.Y. Huang, Optimierung der Spannungsreglung einer schleifringlosen Synchronmaschine, 11. Symposium Maritime Elektrotechnik, Elektronik und Informationstechnik, Universität Rostock, 2004 